\title{
A PRÁTICA COMO COMPONENTE CURRICULAR NA FORMAÇÃO INICIAL DE PROFESSORES DE EDUCAÇÃO FÍSICA
}

\author{
PRACTICE AS A CURRICULAR COMPONENT IN PHYSICAL EDUCATION \\ TEACHERS' EDUCATION
}

\section{LA PRÁCTICA COMO COMPONENTE CURRICULAR EN LA FORMACIÓN INICIAL DE PROFESORES DE EDUCACIÓN FÍSICA}

\author{
Camila Rinaldi Bisconsini ${ }^{*}$ Amauri Aparecido Bássoli de Oliveira*
}

Palavras chave:

Currículo.

Educação Física.

Capacitação

profissional.

Prática profissional.

\begin{abstract}
Resumo: $O$ objetivo da pesquisa foi analisar a Prática como Componente Curricular (PCC) no processo de formação inicial em Educação Física - Licenciatura. A investigação envolveu acadêmicos e docentes do curso de Licenciatura em Educação Física de uma universidade pública do Paraná, cuja participação se deu por meio de entrevistas semiestruturadas. Foi realizada a Análise de Conteúdo dos registros, com a utilização do software NVivo 10. Os discentes entrevistados demonstraram desconhecer a PCC, 0 que não foi evidenciado no grupo docente, que apesar de reconhecer a lacuna existente no currículo pela ausência desse componente, apresenta-se predisposto a organizá-lo no curso. É preciso reorganizar a atual constituição curricular, almejando uma formação inicial articulada com o espaço social de intervenção profissional, para que os futuros professores reconheçam esse cenário em suas particularidades e possam atuar conscientes das relações ali constituídas.
\end{abstract}

Keywords:
Curriculum.

Physical Education.

Professional training

Professional

practice.

Abstract: This research looked into Practice as a Curricular Component (PCC) in the process of Physical Education teachers' education. The investigation involved students and professors of the Physical Education School at a public university in the state of Paraná, Brazil, through semi-structured interviews. We carried out content analysis of records using NVivo 10 software. Students showed no knowledge of PCC, which did not happened in the teacher's group, who are willing to organize it into the course despite acknowledging the gap in the curriculum for the absence of that component. The current curriculum has to be reorganized with a view to education interconnected with the social space of professional intervention so that teachers acknowledge this scenario according to their specifics and are aware of the relations established there during there work.

Palabras clave:

Currículo.

Educación Física.

Capacitación

profesional.

Práctica profesional.
Resumen: El objetivo de la investigación fue analizar la Práctica como Componente Curricular (PCC) en el proceso de formación inicial en Educación Física - Licenciatura. La investigación involucró a académicos y docentes del curso de Licenciatura en Educación Física de una Universidad pública de Paraná, cuya participación se dio a través de entrevistas semiestructuradas. Se realizó el análisis de contenido de los registros, con la utilización del software NVivo 10. Los alumnos demostraron desconocer la PCC, lo que no ocurrió en el grupo docente, que a pesar de reconocer la brecha existente en el currículo por la ausencia de ese componente, se muestra dispuesto a organizarlo en el curso. Es necesario reorganizar la actual constitución curricular, buscando una formación inicial articulada con el espacio social de intervención profesional, para que los futuros profesores reconozcan ese escenario en sus particularidades y puedan actuar conscientes de las relaciones allí constituidas.
*Universidade Estadual de Maringá. Maringá, PR, Brasil. E-mail: camibisconsini@gmail.com; aaboliveira@uem.br

Recebido em: 25-09-2017 Aprovado em: 07-02-2018

DOI: http://dx.doi.org/10.22456/1982-8918.76705 (c) (1) (8) Licence 


\section{INTRODUÇÃOO}

A Prática como Componente Curricular (PCC) já foi descrita em diferentes documentos (BRASIL, 2001a, b, c; 2002a, b; 2015). Conforme a última normatização sobre o assunto, à PCC devem ser reservadas 400 horas na formação inicial de professores, de modo que essa carga horária seja distribuída ao longo do curso (BRASIL, 2015).

No Parecer CNE/CP 9/2001 inicia-se a constituição dos propósitos das práticas curriculares, mencionando-as como atividades que perpassam as reflexões sobre a intervenção profissional. Já o Parecer CNE/CP 28/2001 define a prática e o estágio como componentes curriculares distintos, utilizando, de fato, o termo "Prática como Componente Curricular". Ambas as ações deveriam contemplar propostas de articulação com a Educação Básica e constarem nos currículos dos cursos. Mesmo assim havia dúvidas de gestores institucionais no processo de constituição curricular, já que os indicadores legais ainda não foram suficientes para esclarecer o que são as práticas curriculares (REAL, 2012). As próximas normativas forneceram outros indicativos sobre essa ação ao longo da formação inicial, de modo que a Resolução CNE/CP 1/2002 aponta a realização da PCC desde o início do curso com desenvolvimento ao longo da graduação, a Resolução CNE/CP 2/2002 especifica a carga horária da PCC (400 horas) e a Resolução CNE/CP 2/2015 reforça esses pontos das normas anteriores, além de incluir outros elementos gerais acerca da formação de professores.

Sobre a sistematização da PCC em licenciaturas, Real (2012) esclarece que a criação de uma única disciplina para cumprir esse componente não atenderia às exigências da política nacional de formação de professores. Por outro lado, essa ação pode ser diluída ao longo do curso nas diversas disciplinas de caráter propositivo, por meio da relação dialética entre prática e teoria. Para Araujo e Leitinho (2014), as atividades da PCC podem ser projetadas a partir de núcleos ou como integrantes das disciplinas, já que estas estratégias favorecem o intercâmbio de práticas e teorias que se inter-relacionam e se complementam, a fim de diversificar a prática pedagógica dos futuros professores. Entretanto, cabe destacar que a legislação pertinente (BRASIL, 2015) não delimita ou impõe um modelo específico para a organização e o desenvolvimento das práticas curriculares nos cursos.

A PCC é uma forma de articular os diferentes saberes docentes (da formação profissional, disciplinares, curriculares e experienciais), já que permite a comunicação entre professores universitários, licenciandos e professores que atuam junto aos escolares. Esses agentes mobilizam os diversos saberes ao longo da formação e carreira profissional, com rotas que permitem revisitá-los nesse processo, inclusive por meio de contatos com professores das diferentes fases profissionais. De fato, essa troca somente é possível por meio do estreitamento na relação entre os ensinos básico e superior, especificamente nas licenciaturas. As referências dos acadêmicos sobre a profissão se multiplicam quando se diversificam os ambientes e contextos de ensino e aprendizagem, o que também amplia os subsídios de provocação para a reflexão sobre a intervenção profissional e posturas críticas durante as práticas docentes.

De diferentes formas, os cursos de licenciatura em Educação Física (EF) efetivam o estágio supervisionado e muitos estudos já analisaram esse processo (BISCONSINI; FLORES; OLIVEIRA, 2016; FARIAS et al., 2008; IZA; SOUZA NETO, 2015; MAFFEI, 2014; MARTINY; SOUZA; GOMES-DA-SILVA, 2013; MONTIEL; PEREIRA, 2011; SILVA JÚNIOR et al., 2016; TÉO, 2013). Todavia, apesar de fazer parte da mesma resolução do estágio e ter a carga horária idêntica a este componente do curso, foram encontrados poucos estudos que, de algum modo, 
discutiram as práticas curriculares em cursos de licenciatura em EF (ARAUJO; LEITINHO, 2014; MAFFEI, 2014; MARCON; NASCIMENTO; GRAÇA, 2007; SOUZA NETO; SILVA, 2014). Dentre as principais evidências desses estudos, destacam-se: 0 desconhecimento de docentes e acadêmicos sobre a proposta da PCC e os meios para encaminhá-la nos cursos; o engano de que esse componente já é contemplado por meio do estágio curricular supervisionado (ECS); o desconhecimento da PCC como exigência nos cursos de licenciatura. Ainda, os autores esclarecem a importância das práticas curriculares para a constituição da identidade profissional, a experimentação em cenários reais de ensino junto a escolares e a oportunidade de aprender os conteúdos específicos da área simultaneamente na universidade e nas escolas.

Nesse caminho, a PCC precisa ser mais bem discutida nas pesquisas, a fim de ressaltála como ação definida por Lei e indispensável para uma formação que se pretenda qualificada. É preciso expandir as pesquisas sobre formação, relacionando a futura atuação profissional e tendo as práticas curriculares como espaço privilegiado de elo entre a formação e o ambiente de trabalho (MAFFEI, 2014).

Se os estudos apresentados mostram que isoladamente o estágio não pode extinguir o choque com a realidade e que os licenciandos ainda percebem fragilidades quanto às suas experiências formativas, a Prática como Componente Curricular teria o potencial de otimizar a relação entre universidade e escola, favorecendo o contato com a realidade social? Ainda, essa ação é reconhecida pelos docentes e discentes?

Considera-se que a PCC ainda não é legitimada em cursos de licenciatura em EF, o que pode estar fragilizando esses programas de formação por apresentarem poucos elementos sobre a profissão. Além disso, a PCC pode ser uma estratégia para que se constitua uma ponte entre a universidade e as escolas, o que viabiliza encontros mais frequentes dos licenciandos com o espaço social de intervenção docente e uma formação inicial que seja condizente com a rotina profissional. Por sua vez, essa prática pode revelar os conflitos do sistema de ensino aos futuros professores e dar-Ihes condições de decidir suas próprias ações pedagógicas de forma autônoma.

Portanto, o objetivo da pesquisa foi analisar a Prática como Componente Curricular no processo de formação inicial em Educação Física - Licenciatura.

\section{MÉTODOS}

A pesquisa é qualitativa do tipo descritiva (LÜDKE; ANDRÉ, 2013) e foi desenvolvida a partir de um estudo de caso.

Integraram a investigação 41 acadêmicos do último ano do curso de Licenciatura em Educação Física de uma universidade pública do Paraná, sendo 26 (63\%) e 152 (37\%) dos turnos integral e noturno respectivamente. Deste grupo, 22 (54\%) são do sexo feminino e 19 $(46 \%)$ do sexo masculino. Todos os discentes do último ano foram convidados a participar da pesquisa, o que estimativamente totalizaria 48 participantes ${ }^{1}$. Todavia, no momento de coleta dos dados (segundo semestre de 2016), as turmas do integral e do noturno tinham, respectivamente, 24 e 17 acadêmicos formandos ${ }^{2}$ matriculados ${ }^{3}$.

\footnotetext{
1 Na universidade investigada há dois vestibulares por ano, sendo 12 vagas disponíveis para o turno integral e 12 para o noturno em cada uma das provas, de modo que todos os anos podem iniciar duas turmas de 24 alunos no curso de Licenciatura em Educação Física, totalizando 48 acadêmicos. 2 Foram convidados os formandos pelo fato de serem os agentes com mais elementos para responder às perguntas do roteiro de entrevista semiestruturada, já que esta remete às ações que envolvem todo o processo de formação inicial, o que inviabilizava as respostas de discentes dos outros períodos.

3 Esses números são dos controles de frequência gerados pela Secretaria Acadêmica Virtual do Diretório de Assunto Acadêmicos (DAA) da
} 
No Departamento de Educação Física (DEF) da universidade investigada há 42 docentes (Quadro 1). Foram convidados a participar do estudo 19 professores permanentes do curso que em 2016 atuavam na Licenciatura; apesar disso, foram analisadas as entrevistas de 18 docentes, já que um deles solicitou o descarte de seu registro após receber a transcrição por e-mail.

Quadro 1 - Número de professores por condição de trabalho em 2016.

\begin{tabular}{|c|c|c|c|c|}
\hline Licenciatura $^{4}$ & Bacharelado $^{5}$ & Colaborador $^{6}$ & Licença $^{7}$ & Conflito $^{8}$ \\
\hline 19 & 7 & 6 & 5 & 5 \\
\hline \multicolumn{5}{|c}{ TOTAL: 42} \\
\hline
\end{tabular}

Fonte: Os pesquisadores.

Do grupo de professores participantes ( $f 18)$, oito (44\%) são do sexo feminino e dez $(56 \%)$ do sexo masculino. Em relação à formação, três (16,67\%) são mestres e $15(83,33 \%)$ são doutores. O professor com maior tempo de atuação trabalha como docente no DEF há 36 anos e o professor contratado há menos tempo iniciou o trabalho docente nessa instituição em 2015.

A entrevista semiestruturada foi 0 instrumento que permitiu coletar as informações necessárias para atingir o objetivo da pesquisa. A vantagem que se destaca na entrevista semiestruturada em relação a outras técnicas é que ela permite abordar diferentes assuntos e aprofundar pontos que interessem ao pesquisador e ao próprio entrevistado, o que se mostra limitado com o questionário, por exemplo (LÜDKE; ANDRÉ, 2013). Os roteiros de entrevista foram elaborados pelos pesquisadores a partir de matrizes que nortearam a formulação dos pontos abordados9.

Todas as entrevistas foram realizadas no DEF. As gravações foram realizadas apenas em áudio, em seguida foram transcritas e enviadas a cada um dos participantes para que fizessem a leitura e confirmassem se o texto encaminhado correspondia exatamente à sua fala. Todos os professores e acadêmicos participantes responderam o e-mail para validação das entrevistas.

Foi utilizado o software NVivo 10 para a organização e sistematização dos resultados, além da metodologia Análise de Conteúdo (AC) (BARDIN, 2016). Portanto, a análise dos dados foi realizada pelas seguintes ações: 1) leitura e interpretação das entrevistas transcritas; 2) organização das entrevistas no NVivo (fontes) com classificação por atributos; 3) definição e descrição das categorias (nós e sub-nós) a partir dos objetivos da pesquisa e das entrevistas; 4) codificação a partir das unidades de registro; 5) categorização dos fragmentos nos nós e sub-nós; 6) análise dos resultados. Essas etapas inter-relacionadas incluem: a seleção dos documentos (entrevistas transcritas), a exploração do material, a codificação em unidades de registro, o agrupamento em categorias, a descrição das categorias e a interpretação dos resultados. Tanto a categorização quanto a codificação fazem parte da Análise de Conteúdo (CAREGNATO; MUTTI, 2006), em que na segunda são selecionadas as unidades de registro

universidade investigada.

4 Dos 19 professores, seis atuavam só na Licenciatura e 13 na Licenciatura e no Bacharelado.

5 Professores que atuavam só no Bacharelado em Educação Física.

6 Professores com cargo temporário no Departamento de Educação Física.

7 Professores com licença para fazer o Doutorado/Pós-Doutorado, além da Licença Sabática ou Especial.

8 Dos cinco professores, quatro foram membros de banca da tese que originou o presente artigo e um tem grau de parentesco com a pesquisadora. Portanto, pela condição de conflito de interesse, esses professores não participaram da pesquisa. 
e na primeira estes mesmos fragmentos são agrupados conforme suas características. Desse modo, associar os instrumentos do NVivo às técnicas da AC foi pertinente para a organização e interpretação dos resultados.

A pesquisa ocorreu com o consentimento de todos os participantes, os quais assinaram o Termo de Consentimento Livre e Esclarecido. O projeto passou por análise do Comitê Permanente de Ética em Pesquisa com Seres Humanos - COPEP da universidade em que a pesquisa foi realizada e foi aprovado no Parecer $n-1.710 .582$.

\section{RESULTADOS E DISCUSSÃO}

As dimensões que abarcam as representações dos acadêmicos e professores sobre a PCC no curso de Licenciatura em EF incluem: a defesa da aproximação com a escola desde o início do curso por meio de observações ou vivências, antes mesmo do estágio supervisionado; a dispensabilidade de ir à escola sem ser por meio do ECS; e a própria interpretação da PCC na formação inicial. A organização de apresentação dos resultados foi delimitada a partir dessas categorias, conforme os objetivos da pesquisa e dos elementos que emergiram no decorrer da manipulação dos dados no NVivo. Desse modo, a PCC na formação inicial em EF é a categoria principal (nó) e as demais categorias (sub-nós) são temas dos Quadros de 2 a 6 . A seleção das unidades de registro (codificação) foi seguida pela categorização, que permitiu a organização destes fragmentos conforme sua similaridade. No total foram 59 fontes (entrevistas) e 163 referências (unidades de registro). Não é possível expor todos esses fragmentos, mas serão apresentados aqueles representativos das impressões dos participantes acerca do tema averiguado.

Sobre a organização das atividades no curso de Licenciatura em EF, há os que defendem observações no espaço escolar desde o início do curso, conforme os registros apresentados no Quadro 2.

Quadro 2 - Unidades de registro que ilustram propostas de aproximação com a escola desde o início do curso de Licenciatura em Educação Física por meio de observações.

\begin{tabular}{|c|c|}
\hline ENTREVISTADO(A) $)^{10}$ & $\begin{array}{r}\text { UNIDADE DE REGISTRO } \\
\hline \text { A1 }\end{array}$ \\
\hline A17 & $\begin{array}{r}\text { Nesde os primeiros anos, a gente poderia ter essa oportunidade de ir até a escola, } \\
\text { observar, talvez não fazer nenhuma intervenção ainda. }\end{array}$ \\
\hline A40 & $\begin{array}{r}\text { acadêmico para estar se familiarizando, pegando gosto, vendo } \\
\text { se é aquilo mesmo, se não é. }\end{array}$ \\
\hline P9 & $\begin{array}{r}\text { Se tivesse, até no primeiro, no segundo ano, uma matéria, ou um conteúdo em que o } \\
\text { professor levasse lá, assim: "essa é a realidade", pelo menos para observar, não que } \\
\text { a gente já vá dar aula, porque talvez nem tenha base para isso, mas para observar, } \\
\text { eu acho que seria bem interessante. }\end{array}$ \\
\hline $\begin{array}{r}\text { Por mais que você se esforce na sala de aula para passar bem o conteúdo, nada } \\
\text { melhor que a experiência prática, e você levar o aluno para que ele observe, ou talvez } \\
\text { até em alguns momentos interfira, auxiliando, para que ele já consiga visualizar e } \\
\text { perceber o que ele pode enfrentar no futuro depois de formado estando na escola, } \\
\text { vendo as dificuldades, as facilidades, e até já projetando futuras intervenções na } \\
\text { escola, eu acho muito legal. }\end{array}$ \\
\hline
\end{tabular}

Fonte: Os pesquisadores.

10 Ao longo da apresentação dos resultados, os acadêmicos serão identificados com a letra "A" e os professores com a letra "P". 
Os registros representam a perspectiva daqueles que apontam a possibilidade de os acadêmicos realizarem observações nas escolas públicas desde o início do curso, a fim de se familiarizarem com esse contexto. De acordo com Montiel e Pereira (2011), as atividades pedagógicas que exigem observações em escolas permitem o constante movimento dos licenciandos entre estas e a universidade, com maior preparação do acadêmico para 0 enfrentamento da profissão. Ao apontar as resoluções que destacam a carga horária dos cursos de licenciatura, Souza Neto, Sarti e Benites (2016) lembram a possibilidade de realizar observações em escolas com supervisão especializada.

Na sistematização da PCC em cursos de licenciatura, uma ação possível é a observação em escolas, a partir de uma proposta pedagógica que tenha objetivos claros para essa atividade, em que os acadêmicos reconheçam os motivos pelos quais estão observando um cenário específico (das aulas de EF, no intervalo, de reuniões pedagógicas ou outras práticas da comunidade escolar). Conforme Maffei (2014), uma das finalidades da PCC é promover a observação da prática profissional. Ainda, Casey e Fletcher (2012) destacam que observar colegas experientes pode beneficiar a aprendizagem dos futuros professores sobre como ensinar nas aulas de EF.

Também existem acadêmicos e professores que defendem vivências nas escolas, antes mesmo do estágio supervisionado, e justificam suas posições, conforme registros do Quadro 3.

Quadro 3 - Unidades de registro que ilustram a defesa das vivências de ensino em escolas desde o início do curso de Licenciatura em Educação Física.

\begin{tabular}{|c|c|}
\hline ENTREVISTADO(A) & UNIDADE DE REGISTRO \\
\hline A15 & $\begin{array}{r}\text { Quando você sai, você observa, não faz, não age, não trabalha, você não está ali } \\
\text { na frente tentando fazer, você está ali sentado olhando, observando, vendo como os } \\
\text { outros trabalham. Falta você aplicar também, aproveitar a oportunidade: } \\
\text { "vai ali e faz", "erra agora". }\end{array}$ \\
\hline A20 & $\begin{array}{r}\text { Eu acho que a gente tinha que ter mais esse contato, não deixar só para a disciplina } \\
\text { de estágio esse contato com a escola, porque estágio passa rápido. Se a gente } \\
\text { tivesse determinadas disciplinas, se tivesse essa oportunidade de ir ao colégio, ou } \\
\text { de aplicar uma aula lá na turma, ou trazer isso pra cá e aplicar aqui, eu acho que } \\
\text { seria bom, e o professor vendo, analisando, seria importante, para a nossa profissão, } \\
\text { depois, seria muito válido. }\end{array}$ \\
\hline A39 & $\begin{array}{r}\text { Tinha que ter essa liberdade de um tempo ficar no sexto ano, depois no sétimo, } \\
\text { oitavo, nono, para vivenciar as realidades. }\end{array}$ \\
\hline P8 & $\begin{array}{r}\text { Vamos imaginar assim, o estágio começa, no nosso curso aqui, na segunda metade, } \\
\text { agora você imagina a Prática como se ela fosse preparação [...] } \\
\text { porque ela dá sustentação. }\end{array}$ \\
\hline P17 & $\begin{array}{r}\text { É muito melhor você aplicar uma coisa e ver de fato como ela acontece no mundo } \\
\text { real, do que você ficar só conjecturando e o aluno ter que contar com a experiência do } \\
\text { professor para acreditar que aquilo vai dar certo. }\end{array}$ \\
\hline
\end{tabular}

Fonte: Os pesquisadores.

Os acadêmicos e professores justificam que experienciar certas práticas desde o início do curso é importante para estrear o contato com o futuro espaço profissional, reconhecer essa rotina e suas nuances. Além disso, os registros demonstram como essas vivências podem contribuir para minimizar os desafios do estágio e potencializar a preparação para esse momento.

Em uma de suas pesquisas, Neira (2014, p. 68) questiona: "Se os estágios não promovem uma aproximação qualificada e baseada na reflexão sobre a realidade, como evitar que o egresso entre em choque?", e afirma que os egressos de licenciatura em EF não têm os 
conhecimentos mínimos necessários para compreender a atual realidade educacional e intervir coletiva e criticamente. Uma unidade de registro do Acadêmico 9 expressa parcialmente essa questão: "Talvez uma vivência até antes do estágio do quarto ano, [...] talvez no primeiro e no segundo ano, seria melhor, até pra gente já ter uma experiência a mais, não chegar lá tão [...]: 'não sei o que fazer"'.

Ampliar a perspectiva sobre as escolas é importante para que justamente os recémformados não iniciem a profissão de modo tão desarticulado do ambiente interventivo e desorientados em relação aos conflitos que o envolvem. Não é possível afirmar que a PCC pode definitivamente evitar o choque com a realidade (seja no ECS ou no início da profissão), mas, se bem sistematizada e fiel aos seus objetivos formativos, pode contribuir para fragilizá-lo.

Existem os entrevistados que são ainda mais explícitos sobre a contribuição das vivências de ensino desde o início do curso, como a Acadêmica 19: "Eu tenho uma visão mais idealizada, já deveria começar desde o primeiro ano para ser uma troca entre teoria e prática, e a gente só tem o terceiro e o quarto ano obrigatoriamente para estar fazendo essa prática". Ainda, a Acadêmica 31 detalha os motivos para defender outras vivências além do ECS: "Aqui nós estamos entre quatro paredes e não estamos próximos dos alunos, é outra realidade. Então, desde o primeiro ano, ou segundo, se pudesse oferecer aos alunos, dar essa oportunidade de ir, seria de grande contribuição".

Sair da universidade, aprender em outros espaços, observar, registrar, discutir, problematizar é uma dinâmica que parece ainda ser muito frágil no curso investigado, já que os acadêmicos entrevistados registram as possíveis contribuições de outras práticas, que não só o ECS. Ter os conhecimentos mínimos necessários para compreender a atual realidade educacional e intervir coletiva e criticamente (NEIRA, 2014) requer fraturas no currículo e em antigas estratégias para formar os professores de $E F$, demanda esforços do corpo docente em repensar suas práticas, a fim de reforçar as estratégias positivas e reestruturar aquelas que pouco acrescentam para o conjunto de saberes que sustentam a prática profissional do professor. Iza e Souza Neto (2015, p. 121) destacam:

\footnotetext{
Não temos analisado as nossas práticas de (o) ensino com o cuidado que elas merecem, apesar das experiências isoladas. De modo que muitos temas começam a ser uma paisagem comum no cenário da docência, não se dando a devida atenção. A aprendizagem da docência tem ficado circunscrita à observação e tentativa-erro, podendo essa experiência de ensino ser planejada ou não.
}

Por outro lado, há quem não defenda observações ou vivências nas escolas desde 0 início do processo formativo, como a Acadêmica 3: "Eu não acredito que a gente precisaria ir à escola sempre, desde o início da graduação", cuja ideia é corroborada pelo Acadêmico 41: "Eu não sei se é interessante estar tão antes com uma imaturidade, porque hoje a pessoa entra na graduação com 16/17 anos [...] eu acho até perigoso". No mesmo caminho, a Professora 13 esclarece:

Eu penso que essa tendência de que o aluno vá para a escola, que o futuro professor comece a desenvolver experiências pedagógicas já nos primeiros anos de formação, eu acho um tanto problemático. Eu acho que tem que ter muito claro na organização do curso, do corpo docente, com relação à estrutura da própria formação desse professor para que ele não vá lá para desenvolver suas experiências de ensino sem ter os fundamentos necessários para isso [...]. Eu percebo que o aluno de primeiro ano, por conta de todos os problemas educacionais acumulados que nós temos, entra para uma formação de professores com uma 
capacidade de leitura, de escrita, de compreensão da realidade muito limitada, então não dá para pegar esse aluno que já vem de um processo de educação muito precarizado e fazer com que ele vá à prática e produza essa mesma lógica.

A Professora 13 não defende que os acadêmicos tenham contato com as escolas desde o início da graduação, pois considera que esses alunos ainda não têm os conhecimentos necessários para realizar atividades pedagógicas no ambiente escolar, muito em função das próprias defasagens do sistema de ensino brasileiro. Ela defende, ainda, que efetivar essas práticas demanda envolvimento do corpo docente, com objetivos claros e organização para cumpri-las. Marcon, Graça e Nascimento (2013) salientam que, nos cursos de formação inicial em EF, no momento do planejamento de práticas pedagógicas com alunos em fase escolar, é preciso dedicar atenção à leitura do contexto de intervenção. $O$ desenvolvimento da PCC envolve planejamento, acompanhamento docente e constante avaliação das ações. Antes de promover quaisquer atividades pedagógicas em que os acadêmicos estejam em contato com o cenário escolar, é preciso preparar antecipadamente as ações na universidade e discuti-las, a fim de que cumpra seu objetivo (conforme intenções formativas do professor responsável) e não perturbe os trabalhos da escola.

No Quadro 4 são apresentados os fragmentos das entrevistas realizadas com os acadêmicos, no momento em que são questionados sobre o seu conhecimento acerca das práticas curriculares. Vale destacar que o objetivo neste instante foi compreender como a PCC é veiculada no curso investigado, se é efetivada, e mesmo se os discentes reconhecem esse termo.

Quadro 4 - Unidades de registro que ilustram a perspectiva discente sobre a PCC.

\begin{tabular}{|c|c|}
\hline ACADÊMICO(A) & UNIDADE DE REGISTRO \\
\hline A7 & $\begin{array}{c}\text { Da questão de como eu vou levar o meu aluno a uma prática [...] daqueles conteúdos } \\
\text { estruturantes, de como eu vou fazer para ele cumprir todos aqueles conteúdos. } \\
\text { Mas talvez eu esteja enganada. }\end{array}$ \\
\hline A19 & $\begin{array}{c}\text { É relativo a essa questão das horas que você deve ter para poder concluir a sua } \\
\text { graduação, tanto no estágio obrigatório como no não obrigatório [...]. Talvez tenha tido } \\
\text { alguma associação com essas práticas que a gente tem, de vivência que os professores } \\
\text { levaram fora da escola, ou aqui nas aulas práticas, mas só, foi uma coisa } \\
\text { que eu posso chamar de rasa, muito rasa. }\end{array}$ \\
\hline A25 & $\begin{array}{c}\text { Seria esse diálogo com as disciplinas que nós temos, com as práticas na escola e } \\
\text { tudo mais [...] deveria ser presente em todos os cursos de licenciatura, fora o estágio } \\
\text { obrigatório, essas práticas curriculares deveriam existir, não sei se é o caso de } \\
\text { todos os cursos, mas eu não vejo muito aqui no nosso. }\end{array}$ \\
\hline A32 & $\begin{array}{c}\text { Eu ouvi que a gente tem que ter a prática, faz parte do componente curricular [...] como } \\
\text { as aulas que a gente faz aqui na própria universidade com os alunos, como se fosse } \\
\text { uma aula no colégio também, alguns professores tratam disso e explicam que é muito } \\
\text { importante para o nosso desenvolvimento e para saber como será na escola quando a } \\
\text { gente chegar lá. Mas também tem professores que simplesmente citam e não explicam } \\
\text { como. }\end{array}$ \\
\hline A40 & $\begin{array}{l}\text { Não ouvi falar, mas eu imagino o que seja [...] que é você [...] deixa eu ver como eu vou } \\
\text { explicar, a prática não ser dentro da universidade, você poder ir para outros [...] ou na } \\
\text { escola, seria isso mais ou menos. }\end{array}$ \\
\hline
\end{tabular}

Fonte: Os pesquisadores.

Os fragmentos apresentados no Quadro 4 demonstram que a Prática como Componente Curricular ainda não é uma ação consolidada no curso de Licenciatura em EF, já que os acadêmicos titubeiam ao tentar explicar esse termo, indicando desconhecimento dessa possibilidade. Nenhum deles citou este componente como integrante da carga horária do curso, ou como uma prática organizada e articulada aos demais componentes curriculares. Em pesquisa realizada por Barbosa et al. (2013), os resultados demonstraram que 35,7\% 
dos licenciandos e 33,3\% dos professores indagados desconheciam o termo "Prática como Componente Curricular", além de confundir esta prática com o ECS.

Logo no título de seu artigo, Real (2012) questiona: "A prática como componente curricular: o que isso significa na prática?"; e ressalta que os indicadores legais não foram suficientes para esclarecer o que é essa ação. No caso da realidade investigada na presente pesquisa, mesmo após a resolução que reforça a exigência das 400 horas de PCC (BRASIL, 2015), ainda há desentendimento sobre o encaminhamento dessa atividade.

A legislação (BRASIL, 2001a,b, 2002a,b, 2015) apresenta os seguintes indicativos sobre a PCC: definição da carga horária11 (400h); articulação com o ECS; integração ao Projeto Pedagógico de Curso; desenvolvimento ao longo da graduação, com distribuição entre todas as disciplinas; é um meio de integração entre as instituições de ensino básico e superior; e inclui atividades em situações reais de ensino. Há, portanto, orientações sobre a organização das práticas curriculares nas licenciaturas, as quais permitem, sobretudo, que cada curso delineie esta atividade pedagógica de acordo com as suas particularidades estruturais e pedagógicas. Cabe aos cursos, especificamente ao grupo docente, organizar-se para atender as prerrogativas, a fim de qualificar o processo formativo.

Os professores investigados identificam a PCC como uma exigência para os currículos na formação de professores, e esclarecem sua atual situação no curso de Licenciatura em EF (Quadro 5).

Quadro 5 - Unidades de registro que ilustram a perspectiva docente sobre a PCC no curso de Licenciatura em Educação Física.

\begin{tabular}{|c|c|}
\hline PROFESSOR(A) & UNIDADE DE REGISTRO \\
\hline P1 & $\begin{array}{c}\text { Eu percebo que não está bem estruturado isso, eu não diria que } \\
\text { está acontecendo efetivamente. }\end{array}$ \\
\hline P3 & $\begin{array}{c}\text { Há necessidade de se definir o formato e os professores precisam dar conta desse formato. } \\
\text { Então, eu entendo que ela precisa ser alvo de discussões internas do Departamento, para } \\
\text { que se chegue a um formato que contemple as necessidades dos alunos. Acredito que ela } \\
\text { tenha que ser sistematizada, e que essa sistematização precise ser discutida para que se } \\
\text { chegue a um consenso e os docentes consigam atuar de forma homogênea. }\end{array}$ \\
\hline P6 & $\begin{array}{c}\text { Atualmente não está bem claro para a maioria dos professores, por isso nós estamos } \\
\text { em discussão em relação a isso [...]. Então acho que hoje, se deixar bem claro para os } \\
\text { professores como será essa distribuição, vai facilitar o trabalho deles, porque muitos devem } \\
\text { estar fazendo porque acham importante, mas isso não está dentro da carga horária. }\end{array}$ \\
\hline P16 & $\begin{array}{c}\text { Essa é a visão que eu tenho, que as práticas curriculares na verdade não existem. [...] essa } \\
\text { é a impressão que eu tenho nos cursos de licenciatura como um todo. }\end{array}$ \\
\hline P19 & $\begin{array}{c}\text { Esse é um assunto que esse ano foi e está sendo discutido [...]. Eu acho que depende } \\
\text { de cada professor, muitas vezes realiza alguma ação que vá nesse direcionamento, de } \\
\text { Prática como Componente Curricular [...]. Eu percebo ainda como práticas mais isoladas, } \\
\text { dependendo de quem está à frente da disciplina, e vejo que há um movimento para tornar } \\
\text { isso mais sistemático, planejado, enfim, mais organizado para os próximos anos. }\end{array}$ \\
\hline
\end{tabular}

Fonte: Os pesquisadores.

Por meio das unidades de registro apresentadas é possível inferir que no curso de Licenciatura em EF há o início de discussão sobre as possibilidades de organização da PCC no currículo, ao mesmo tempo, parece que tal discussão ainda não alcançou todos os professores

\footnotetext{
11 Conforme a Resolução CNE/CP 2/2015 (p. 10-11): "§ 1ํOs cursos de que trata o caput terão, no mínimo, 3.200 (três mil e duzentas) horas de efetivo trabalho acadêmico, em cursos com duração de, no mínimo, 8 (oito) semestres ou 4 (quatro) anos, compreendendo: I - 400 (quatrocentas) horas de prática como componente curricular, distribuídas ao longo do processo formativo; II - 400 (quatrocentas) horas dedicadas ao estágio supervisionado [...]; III - pelo menos 2.200 (duas mil e duzentas) horas dedicadas às atividades formativas estruturadas pelos núcleos definidos nos incisos I e II do artigo 12 desta Resolução, conforme o projeto de curso da instituição; IV - 200 (duzentas) horas de atividades teórico-práticas de aprofundamento em áreas específicas de interesse dos estudantes".
} 
do Departamento, demonstrando que é uma proposta em fase inicial de desenvolvimento. Os fragmentos ainda evidenciam que há, por enquanto, especulações no grupo docente sobre o que são e como serão efetivadas as práticas curriculares.

Apesar do receio sobre a organização e as possíveis limitações institucionais, os professores apresentam-se favoráveis ao debate e às propostas de organização da PCC no curso. Desse modo, vale aproveitar essa predisposição para novas iniciativas pedagógicas e o início de uma reestruturação curricular, a fim de contribuir para a formação inicial dos acadêmicos de licenciatura em EF, proporcionando-lhes a diversificação de experiências de ensino e o maior contato com a Educação Básica.

Sobre o entendimento da PCC, Costa e Tiago (2016) afirmam que uma das dificuldades encaradas pelas licenciaturas é a interpretação destas práticas, o que reflete nas diversas formas de implementá-las nos currículos. No estudo de Araujo e Leitinho (2014), que envolveu professores universitários de um curso de licenciatura em EF, as autoras revelam que a maioria dos docentes não tem conhecimento sobre o que é a PCC e a sua importância para a formação inicial. Em pesquisa realizada por Souza Neto e Silva (2016) com 40 cursos de licenciatura, constatou-se que a PCC é alocada em disciplinas de conteúdos específicos, de fundamentos da educação, ou no ECS; além disso, um dos cursos não tinha esse componente.

Por enquanto, há a necessidade de esforços para reconhecer e efetivar essas práticas nos cursos de licenciatura em EF. É preciso provocar pequenos abalos em um processo que parece ainda muito linear e constante em suas iniciativas de mudanças curriculares, o que demanda o envolvimento dos agentes em trabalho, que no dia a dia de suas aulas percebem as fragilidades do processo e pensam possibilidades de mudanças. É a soma de elementos que constituem a rotina profissional desses docentes entre ensino, pesquisa e extensão que resulta no desvelamento do que é necessário manter, reforçar ou modificar no curso.

Ainda há professores que destacam os possíveis reflexos da PCC na qualidade da formação inicial, com ações que vão além das vivências de ensino. Estes registros são expostos no Quadro 6.

Quadro 6 - Os possíveis reflexos da PCC na qualidade da formação inicial em Educação Física, na perspectiva docente.

\begin{tabular}{|c|c|}
\hline PROFESSOR(A) & UNIDADE DE REGISTRO \\
\hline P8 & $\begin{array}{r}\text { Não dá mais para fazer um engodo, não dá mais para deixar a Instituição Superior longe da } \\
\text { Educação Básica. E essas práticas curriculares têm a possibilidade de fazer com que haja } \\
\text { entrelaçamento. [...] Acho que já passou da hora. }\end{array}$ \\
\hline P10 & $\begin{array}{r}\text { Eu vejo que depende muito do professor, mas não simplesmente trazer de uma forma } \\
\text { ingênua a prática para dentro da escola ou levar o aluno para a prática de uma forma } \\
\text { ingênua. [...] Você fazer essa relação com a prática não é simplesmente levando eles lá } \\
\text { para dentro, mas é você trazer vídeos, conteúdos de apoio, falar, propor reflexões nesse } \\
\text { sentido, possibilitar ao aluno questionamento dessa realidade, trazer } \\
\text { uma série de ferramentas que auxiliam. }\end{array}$ \\
\hline P11 & $\begin{array}{c}\text { As práticas permitem isso, o que a gente teve lá no primeiro semestre pode ser feito desse } \\
\text { jeito: "Professor, eu percebi que tal aluno conseguiu fazer de uma maneira e o outro não", } \\
\text { então isso vai, de certa forma, dizendo a ele: "Isso é ser professor". Muitas vezes eles terão } \\
\text { essa ideia no fim do terceiro, começo do quarto ano, e aí às vezes os primeiros anos foram } \\
\text { feitos de qualquer maneira, e agora ele precisará desse conteúdo do primeiro, do segundo, } \\
\text { para aplicar na escola, e eu vejo que as práticas curriculares já contribuem para isso, para } \\
\text { dizer assim: "Você vai precisar disso, você vai precisar levar esse conteúdo para a escola". } \\
\text { Então, como isso vai se dar? Eu vejo de uma forma muito positiva e formativa as práticas } \\
\text { curriculares. }\end{array}$ \\
\hline
\end{tabular}


A Professora 8 destaca que a efetivação da PCC não pode ser adiada no curso e que esta ação permitirá a articulação entre a universidade e a Educação Básica, com pontes de comunicação entre as duas instâncias de ensino. O processo de formação inicial de professores deve promover a aproximação entre os conhecimentos teórico-práticos aprendidos na universidade com os conhecimentos advindos da realidade profissional (BARBOSA et al., 2013), o que requer uma relação de integração entre as licenciaturas e as escolas.

O Professor 10 ressalta que os encontros, as observações ou vivências de ensino em escolas devem ser atividades planejadas em seus propósitos formativos, que envolvam situações próprias dessa realidade e que sejam problematizadas no decorrer das disciplinas. Para ele, as práticas curriculares somente terão significado para os acadêmicos se forem refletidas e debatidas por meio de recursos diversificados, caso contrário, não cumprirão com o objetivo de aproximar o discente das particularidades de seu futuro espaço profissional. Desse modo, "a PCC é uma forma específica da 'práxis'; é uma dimensão dirigida por objetivos, finalidades e conhecimentos, vista de forma mais ampla" (ARAUJO; LEITINHO, 2014, p. 91), ou seja, é uma ação que demanda organização e objetivos bem definidos dentro do currículo.

Também, para o Professor 11, outra possível dimensão acarretada pela PCC é a percepção do perfil profissional de um professor de EF. Ele destaca que essa visão é possível logo no início do curso e não deveria ser possibilitada apenas no final da formação, desarticulando os saberes. Caso as práticas curriculares sejam oportunizadas ao longo da graduação, os saberes curriculares e experienciais serão intercambiados, o que pode potencializar o processo ensino-aprendizagem. A PCC é um espaço de discussão sobre a prática profissional (MAFFEI, 2014) que fortalece uma formação condizente com a realidade de trabalho do professor.

Portanto, as perspectivas dos professores (Quadro 6) exemplificam possíveis reflexos da Prática como Componente Curricular na formação inicial em EF e indicam receptividade docente quanto à consolidação dessa proposta, a fim de estreitar a relação entre as disciplinas e a Educação Básica.

Na realidade pesquisada, a PCC pode ser uma nova proposta na formatação do atual currículo, pois sua organização implicaria a reestruturação dos demais componentes a fim de que haja carga horária destinada a essa ação e que seja desenvolvida de modo interdisciplinar, permeando todo o curso. Essas alterações curriculares seriam provocadas para estabelecer uma ponte entre universidade e escolas, além de aproximar estes ambientes de formação docente, o que requer, inicialmente, predisposição do corpo docente, o que parece existir no curso, ou seja, há o início da discussão entre parte deste grupo para instigar uma proposta de PCC na licenciatura em EF. Essa movimentação inicial que parte do campo universitário pode ter reflexos positivos na qualidade da formação, que contaria com a diversificação de práticas para abordar os saberes disciplinares.

Considerando, ainda, a formação social e o sistema de ensino institucionalizado que cercam as relações dos agentes vinculados à formação inicial de professores, a PCC pode contribuir para desvelar contradições dessa dinâmica, já que viabiliza a integração dos licenciandos ao contexto da Educação Básica. Ao ampliar o olhar sobre esse sistema há maiores chances de analisá-lo criticamente, desde que haja mediação dos professores universitários e oportunidades de problematizar as situações observadas ou vivenciadas com a turma no ensino superior. 
A partir dessa perspectiva, também é possível e bastante provável que se formem professores mais conscientes sobre a realidade em que atuam, com recursos didáticos que, em certa medida, partem das atividades oportunizadas no período da graduação. Para que os professores de EF tenham uma postura ativa e autônoma nas escolas é preciso munilos de referências sobre o contexto interventivo, a partir da diversificação de fontes, o que envolve leituras, observações, vivências, variação de cenários e situações, debates. Nesse sentido, o sistema de ensino precisa ser veiculado nos programas de formação por meio dos aspectos conceituais e experienciais. Em outras palavras, é preciso um olhar mais profundo sobre a formação social dominante do qual o ensino faz parte e a observação direta desse mesmo sistema. Pela imersão nesse contexto e compreensão dos seus conflitos, os futuros professores poderão manter ou transformar antigas posturas na área da EF, cabe aos cursos oferecer subsídios para que essas escolhas sejam, de fato, conscientes.

\section{CONSIDERAÇÕES FINAIS}

Apesar da lacuna existente no currículo pela inexistência da PCC, os docentes identificam essa ação, ao contrário dos acadêmicos, que denotam desconhecê-la, pois não há compreensão deste componente como integrante da formação de professores. Este é um fato que revela a ausência das práticas curriculares no curso, além de evidenciar a carência na abordagem das normativas que dizem respeito aos cursos de licenciatura. Assim, o debate iniciado em parte do grupo de professores para encetar o processo de planejamento da PCC ainda não alcançou os discentes, por outro lado, estes se apresentam receptivos a novas atividades pedagógicas que proporcionem encontros com escolas no decorrer da graduação. Caso a proposta em início de discussão seja efetivada, é possível que se repense 0 atual currículo e uma nova configuração do curso seja desenvolvida, por meio de ações mais articuladas com a Educação Básica.

Ser professor é ensinar por meio da área de formação; envolve as relações profissionais com pais, alunos, diretores, pedagogos; requer compromisso com tarefas que extrapolam suas aulas, como formaturas e reuniões; é frequentar secretarias e núcleos regionais de educação; é depender de políticas que medeiam sua situação profissional; é trabalhar em escolas com diversos materiais e em outras sem estrutura; demanda persistência e responsabilidade. Pouca proximidade com essa complexidade durante a graduação é um incômodo, que pode ser minimizado com a diversificação de práticas desde o início desse processo. Por conhecermos a universidade investigada ${ }^{12}$, entendemos que no curso de Licenciatura em EF há carência de oportunidades para que os estudantes e futuros professores se inteirem dos elementos profissionais vinculados à Educação Básica, o que nos provocou a investigar se essa interpretação era corroborada pelos formandos e docentes.

É preciso dar condições para que os discentes percebam as contradições que persistem nas instâncias escolares. Descortinar este cenário é mais que apresentar produções científicas já existentes sobre o sistema de ensino, envolve dar subsídios para que os futuros professores produzam seus próprios argumentos sobre a realidade apresentada, e, conscientemente, decidam suas ações enquanto formadores. Para tanto, eles precisam sair das universidades, ver os agentes em movimento no dia a dia escolar, problematizar as situações observadas, discuti-las com seus pares, questioná-las aos seus professores, exercitá-las em diversos 
espaços, manter estratégias bem-sucedidas, duvidar de antigas práticas, criar rupturas e planejar suas próprias intervenções, ou seja, sair da zona de conforto, estimularem-se pela curiosidade e pelo desafio constante da escola.

Mais do que não atender uma norma das diretrizes para a formação de professores, a ausência da Prática como Componente Curricular no curso de Licenciatura em EF pode fragilizar o processo formativo, com raras oportunidades de atividades pedagógicas no contexto de intervenção, além do estágio supervisionado. Restringir a observação, vivência e discussão de situações-problema vinculadas à Educação Básica contribui para a conservação dos "choques com a realidade", a desarticulação entre universidade e escolas públicas e para a formação de professores que iniciam a profissão desorientados em relação a peculiaridades da rotina de intervenção docente.

\section{REFERÊNCIAS}

ARAUJO, Raffaelle Andressa dos Santos; LEITINHO, Meirecele Calíope. Reflexões sobre a prática como componente curricular do curso de Licenciatura em Educação Física da Universidade Federal do Maranhão. Motrivivência, v. 26, n. 43, p. 89-103, 2014.

BARBOSA, Alessandro Tomaz et al. Concepção de alunos e professores sobre a Prática como Componente Curricular no curso de formação de professores de Ciências e Biologia. In: CONGRESSO INTERNACIONAL SOBRE INVESTIGACIÓN EN DIDÁCTICA DE LAS CIENCIAS, 2013, Girona/ES. Anais... Girona,Espanha, 2013. p. 270-275.

BARDIN, Laurence. Análise de conteúdo. São Paulo: Edições 70, 2016.

BISCONSINI, Camila Rinaldi; FLORES, Patric Paludett; OLIVEIRA, Amauri Aparecido Bássoli de. Formação inicial para a docência: o Estágio Curricular Supervisionado na visão de seus coordenadores. Journal of Physical Education, v. 27, n. e2702, p. 1-13, 2016.

BRASIL. Ministério da Educação. Conselho Nacional de Educação. Parecer CNE/CP 009/2001. Diretrizes Curriculares Nacionais para a Formação de Professores da Educação Básica, em nível superior, curso de licenciatura, de graduação plena. Brasília, DF, 2001a.

BRASIL. Ministério da Educação. Conselho Nacional de Educação. Parecer CNE/CP 21/2001. Duração e carga horária dos cursos de Formação de Professores da Educação Básica, em nível superior, curso de licenciatura, de graduação plena. Brasília, DF, 2001b.

BRASIL. Ministério da Educação. Conselho Nacional de Educação. Parecer CNE/CP 28/2001. Dá nova redação ao Parecer CNE/CP 21/2001, que estabelece a duração e a carga horária dos cursos de Formação de Professores da Educação Básica, em nível superior, curso de licenciatura, de graduação plena. Brasília, DF, 2001c.

BRASIL. Ministério da Educação. Conselho Nacional de Educação. Resolução CNE/CP no 01 de 18 de fevereiro de 2002. Institui Diretrizes Curriculares Nacionais para a Formação de Professores da Educação Básica, em nível superior, curso de licenciatura, de graduação plena. Brasília, DF, 2002a. 
BRASIL. Ministério da Educação. Conselho Nacional de Educação. Resolução CNE/CP no 02 de 19 de fevereiro de 2002. Institui a duração e a carga horária dos cursos de licenciatura, de graduação plena, de formação de professores da Educação Básica em nível superior. Brasília, DF, 2002b.

BRASIL. Ministério da Educação. Conselho Nacional de Educação. Resolução CNE/CP no 02 de 01 de julho de 2015. Define as Diretrizes Curriculares Nacionais para a formação inicial em nível superior (cursos de licenciatura, cursos de formação pedagógica para graduados e cursos de segunda licenciatura) e para a formação continuada. Brasília, DF, 2015.

CAREGNATO, Rita Catalina Aquino; MUTTI, Regina. Pesquisa qualitativa: análise de discurso versus análise de conteúdo. Texto Contexto Enfermagem, v. 15, n. 4, p. 679-684, 2006.

CASEY, Ashley; FLETCHER, Tim. Trading places: from Physical Education Teachers to Teacher Educators. Journal of teaching in Physical Education, v. 31, n. 4, p. 362-380, 2012.

COSTA, Nicole Faria; TIAGO, Graziela Marchi. A Prática como Componente Curricular nos cursos de Licenciatura em Matemática do IFSP. Revista Univap, v. 22, n. 40, p. 546, 2016.

FARIAS, Gelcemar Oliveira et al. Preocupações pedagógicas de estudantes-estagiários na formação inicial em educação física. Motriz, v. 14, n. 3, p. 310-319, 2008.

IZA, Dijnane Fernanda Vedovatto; SOUZA NETO, Samuel de Souza. Os desafios do estágio curricular supervisionado em Educação Física na parceria entre universidade e escola.

Movimento, v. 21, n. 1, p. 111-123, 2015.

LÜDKE, Menga; ANDRÉ, Marli Eliza Dalmazo Afonso de. Pesquisa em educação: abordagens qualitativas. 2. ed. Rio de Janeiro: E.P.U., 2013.

MAFFEI, Willer Soares. Prática como componente curricular e estágio supervisionado na formação de professores de educação física. Motrivivência, v. 26, n. 43, p. 229-244, 2014.

MARCON, Daniel; GRAÇA, Amândio Braga Santos; NASCIMENTO, Juarez Vieira do. O conhecimento do contexto na formação inicial em educação física. Revista Brasileira de Educação Física e Esporte, v. 27, n. 4, p. 633-645, 2013.

MARCON, Daniel; NASCIMENTO, Juarez Vieira do; GRAÇA, Amândio Braga Santos. A construção das competências pedagógicas através da prática como componente curricular na formação inicial em educação física. Revista Brasileira de Educação Física e Esporte, v. 21, n. 1, p. 11-25, 2007.

MARTINY, Luis Eugênio; SOUZA, Irani; GOMES-DA-SILVA, Pierre Normando. "Como saber se meu mundo de ideias daria certo na prática?" O medo da docência no estágio supervisionado em educação física. Motrivivência, n. 40, p. 51-66, 2013.

MONTIEL, Fabiana Celente; PEREIRA, Flávio Medeiros. Problemas evidenciados na operacionalização das 400 horas de estágio curricular supervisionado. Revista da Educação Física/UEM, v. 22, n. 3, p. 421-432, 2011.

NEIRA, Marcos Garcia. Os currículos que formam professores de educação física e a Síndrome de Estocolmo: explicações para o choque com a realidade. Educación Física y Deporte, v. 33, n.1, p. 51-71, 2014.

REAL, Gisele Cristina Martins. A prática como componente curricular: o que isso significa na prática? Educação e Fronteitas On-Line, v. 2, n. 5, p. 48-62, 2012. 
SILVA JÚNIOR, Arestides Pereira da et al. Estágio curricular supervisionado na formação de professores em educação física: uma análise da legislação a partir da Resolução CFE n 03/1987. Pensar a Prática, v. 19, n. 1, p. 1-14, 2016.

SOUZA NETO, Samuel de; SARTI, Flavia Medeiros; BENITES, Larissa Cerignoni. Entre o ofício de aluno e o habitus de professor: os desafios do estágio supervisionado no processo de iniciação à docência. Movimento, v. 22, n. 1, p. 311-324, 2016.

SOUZA NETO, Samuel de; SILVA, Vandeí Pinto da. Prática como Componente Curricular: questões e reflexões. Revista Diálogo Educacional, v. 14, n. 43, p. 889-909, 2014.

TÉO, Carlos Eduardo. Estágio curricular supervisionado como campo de pesquisa na formação inicial do professor de educação física da UEL. 2013. 177 f. Dissertação (Mestrado em Educação) - Universidade Estadual de Londrina, Londrina/PR, 2013. 
